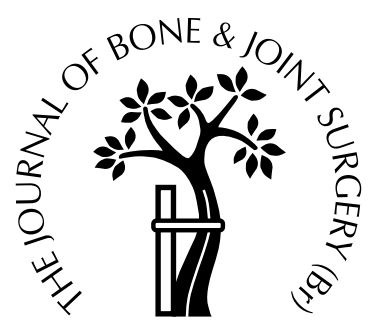

\title{
Arthroplasty of the elbow in haemophilia
}

\author{
P. J. Chapman-Sheath, P. Giangrande, A. J. Carr \\ From the Nuffield Orthopaedic Centre, Oxford, England
}

$\mathbf{T}$ otal elbow replacement can be a valuable option for the treatment of the elbow in haemophilia where there are associated arthropathic changes. We describe the outcome of seven elbow replacements in five consecutive patients with severe haemophilia A (native factor levels $<1 \%$ ) at a mean of 42 months (25 to 65) after operation. All the patients had excellent relief of pain and improvement in function. One failure was due to infection in an immunocompromised patient with both HIV and Hepatitis C antibodies who was on antiretroviral chemotherapy. The implant was revised at 30 months in a one-stage procedure and showed no evidence of loosening or infection 35 months later.

J Bone Joint Surg [Br] 2003;85-B:1138-40.

Received 4 November 2002; Accepted after revision 29 May 2003

The clinical and radiological consequences of severe haemophilia A (native factor levels $<1 \%$ ) and the subsequent recurrent haemarthroses into synovial joints are well documented. ${ }^{1,2}$ Specific arthropathic changes of the elbow joint have also been described. ${ }^{3}$ Much is already known about the genetic basis of the disease, while the eventual arthropathic changes are also understood at both macroscopic and histological levels.

The patient with haemophilia is best managed by a multidisciplinary team since specialist assistance may be required from a broad spectrum of health professionals. ${ }^{4}$ The ability to replace the blood clotting factor has allowed orthopaedic surgery to become a realistic option for treatment. Peri-operatively, patients may be treated either with

P. J. Chapman-Sheath, FRCS Orth, Specialist Registrar in Trauma and Orthopaedics

P. Giangrande, MD, FRCP, Director of Oxford Haemophilia and Thrombosis Centre

A. J. Carr, ChM, FRCS, Nuffield Professor of Orthopaedic Surgery

Nuffield Orthopaedic Centre, Windmill Road, Headington, Oxford, OX3

7LD, UK.

Correspondence should be sent to Professor A.J. Carr.

(C)2003 British Editorial Society of Bone and Joint Surgery

doi:10.1302/0301-620X.85B8.13986\$2.00 bolus injections of factor replacements or by a continuous infusion.

A variety of operations have been used in the elbow including excision arthroplasty, arthrodesis, silastic interposition arthroplasty, excision of the radial head and synovectomy. ${ }^{5-11}$ Excision of the head of the radius combined with arthroscopic or open synovectomy, has yielded consistently good results ${ }^{8}$ with reduction in pain, an increased range of movement and a decrease in the frequency of joint bleeds. Replacement arthroplasty may become necessary if destruction of the joint continues.

\section{Patients and Methods}

We have reviewed the outcome of seven arthroplasties of the elbow in five consecutive severely affected haemophiliac patients, undertaken since 1996. Each patient was seen before operation by the surgeon (AJC) who would carry it out and a member of the haemophilia team and the risks and benefits of joint replacement surgery discussed. The mean age at the time of operation was 48.4 years (31 to 63). There were five right-sided and two left-sided implants. The dominant side underwent surgery in four patients each of whom was right-handed. All patients had severe pain at rest and on movement with a radiological appearance compatible with severe degeneration of the joint. (Fig. 1). Each patient received either a bolus dose of factor replacement or a continuous infusion. An experienced anaesthetist administered the general anaesthesia. All patients received $1.5 \mathrm{~g}$ of intravenous cefuroxime on induction of the anaesthetic and at eight and 16 hours after the operation. Anti-retroviral medication, when prescribed, was stopped seven days before surgery and recommenced seven to 10 days after. All the primary procedures were carried out through a posterior longitudinal skin incision and splitting the triceps. The ulnar nerve was identified in the cubital tunnel and protected throughout the procedure, with avoidance of excessive traction. The head of the radius was excised in a standard manner for all patients. After adequate release of the soft tissues and collateral ligaments, and subsequent bony preparation, the prostheses were inserted using gentamicin-impregnated cement. The ulnar nerve was not transposed. A single wound drain was used and removed within 24 hours. Closure of the wound was 


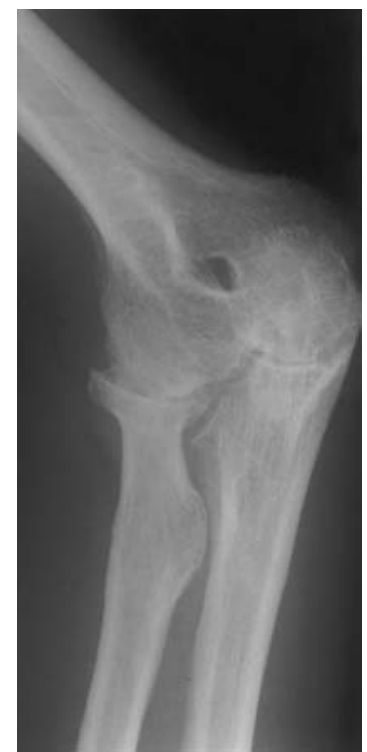

Fig. 1a

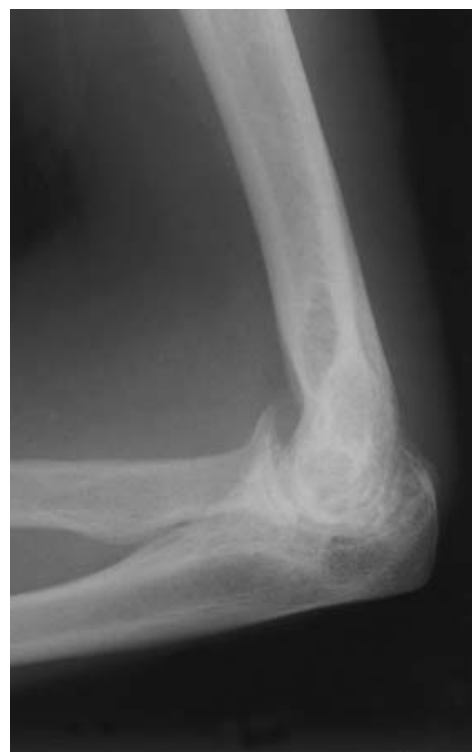

Fig. 1b

Radiographs demonstrating the typical joint destruction which is seen in end-stage haemophilic arthropathy of the elbow.

undertaken in layers using absorbable sutures, but with clips to the skin.

After operation each patient was reviewed by a member of the haemophilia team. Appropriate factor levels were maintained by bolus injections, initially on a twice-daily regime, then once daily after one week post-operatively as dictated by monitoring the blood levels. Patients were mobilised by using an active, assisted, exercise regime for six weeks under the direction of an experienced physiotherapist. No problems were encountered with bleeding or wound healing. Four elbows were managed with unlinked implants, either the Kudo or the Souter-Strathclyde (Biomet Merck Ltd, Bridgend and Stryker Howmedica Ltd, Newbury, UK). The remaining three and the one revision were managed with a Coonrad-Morrey prosthesis (Zimmer Ltd, Swindon, UK). The linked Coonrad-Morrey implant was used where there were concerns for joint stability.

Results

All patients were followed up for a minimum of 25 months after operation (mean 42, 25 to 65). The pre-operative and post-operative data for each patient are presented in Table I. All the patients were satisfied with the outcome.

Range of movement. The mean pre-operative arc of flexion was $50^{\circ}$ (20 to 60 ), the mean fixed flexion deformity was $50^{\circ}$ (10 to 90 ) and the mean flexion was $97^{\circ}$ (80 to 110 ). Post-operatively, the mean arc of flexion was $93.5^{\circ}$ (55 to 110 ), the mean fixed flexion deformity was $28.5^{\circ}$ (10 to 60) and the mean flexion was $122^{\circ}$ (110 to 130$)$.

The mean pre-operative arc of rotation was $33^{\circ}$ which was from $27^{\circ}$ of pronation to $6^{\circ}$ of supination. Post-operatively this improved to $115^{\circ}$, from $59^{\circ}$ of pronation to $56^{\circ}$ of supination. The mean increase in the arc of the rotation was $82^{\circ}$ (25 to 150 ) with a mean gain in pronation of $34^{\circ}$ (0 to 80 ) and a mean gain in supination of $48^{\circ}$ (15 to 70 ).

Pain. All patients had experienced severe pain before operation. At their last review four were free of pain and two experienced mild pain on activity.

Stability. All the elbows were stable at the final review.

Radiological findings. The six surviving primary elbow replacements in the five patients were assessed at the final review. None showed any evidence of progressive radiolucency around either the humeral or the ulnar component. The one elbow (case 1) which had been revised from a Kudo prosthesis to a Coonrad-Morrey device because of septic loosening also showed no evidence of progressive radiolucency (Fig. 2).

Complications. There were three major post-operative complications, one ulnar nerve palsy (case 2) which recovered within six months of surgery and one axillary vein thrombosis (case 4) which was treated conservatively. Another patient with both HIV and Hepatitis C antibodies (case 1) had a one-stage revision of a Kudo prosthesis to a Coonrad-Morrey semi-constrained prosthesis because of septic loosening. The patient experienced pain in the elbow 24 months after the initial operation with a rapid progression to wound breakdown. The infection was initially treated with antibiotics after the isolation of a coagulasenegative staphylococcus. Surgery was required six months

Table I. Case details and clinical outcomes in five patients with haemophilia A who underwent TER

\begin{tabular}{|c|c|c|c|c|c|c|c|c|}
\hline \multirow[b]{2}{*}{ Case } & \multirow[b]{2}{*}{ Side } & \multirow{2}{*}{$\begin{array}{l}\text { Age in } \\
\text { years }\end{array}$} & \multirow{2}{*}{$\begin{array}{l}\text { Follow-up in } \\
\text { months }\end{array}$} & \multirow[b]{2}{*}{ Prosthesis } & \multirow[b]{2}{*}{ HIV/Hepatitis } & \multirow{2}{*}{$\begin{array}{l}\text { Other joints } \\
\text { involved }\end{array}$} & \multicolumn{2}{|c|}{ Arc of flexion in degrees (total) } \\
\hline & & & & & & & Pre-operative & Post-operative \\
\hline 1 & $\mathrm{R}$ & 46 & 46 & Kudo & $\mathrm{HIV}+/ \mathrm{C}+$ & Shoulder arthrodesis & 30 to $90(60)$ & 45 to $130(85)$ \\
\hline 1 & $\mathrm{~L}$ & 49 & 29 & Kudo & $\mathrm{HIV}+/ \mathrm{C}+$ & Shoulder arthrodesis & 60 to $80(20)$ & 20 to $130(110)$ \\
\hline 2 & $\mathrm{R}$ & 37 & 65 & Kudo & $\mathrm{C}+$ & None & 90 to $110(20)$ & 60 to $115(55)$ \\
\hline 3 & $\mathrm{R}$ & 56 & 51 & Souter-Strachclyde & $\mathrm{C}+$ & Knee arthroplasty & 60 to $100(40)$ & 20 to $130(110)$ \\
\hline 4 & $\mathrm{R}$ & 47 & 43 & Coonrad Morrey & $\mathrm{C}+$ & None & 50 to $110(60)$ & 15 to $110(95)$ \\
\hline 5 & $\mathrm{R}$ & 64 & 37 & Coonrad Morrey & $\mathrm{B}+/ \mathrm{C}+$ & $\begin{array}{l}\text { Knee and hip } \\
\text { replacement }\end{array}$ & 30 to $90(60)$ & 30 to $120(90)$ \\
\hline 5 & $\mathrm{~L}$ & 64 & 25 & Coonrad Morrey & $\mathrm{B}+/ \mathrm{C}+$ & $\begin{array}{l}\text { Knee and hip } \\
\text { replacement }\end{array}$ & 10 to $100(90)$ & 10 to $120(110)$ \\
\hline
\end{tabular}




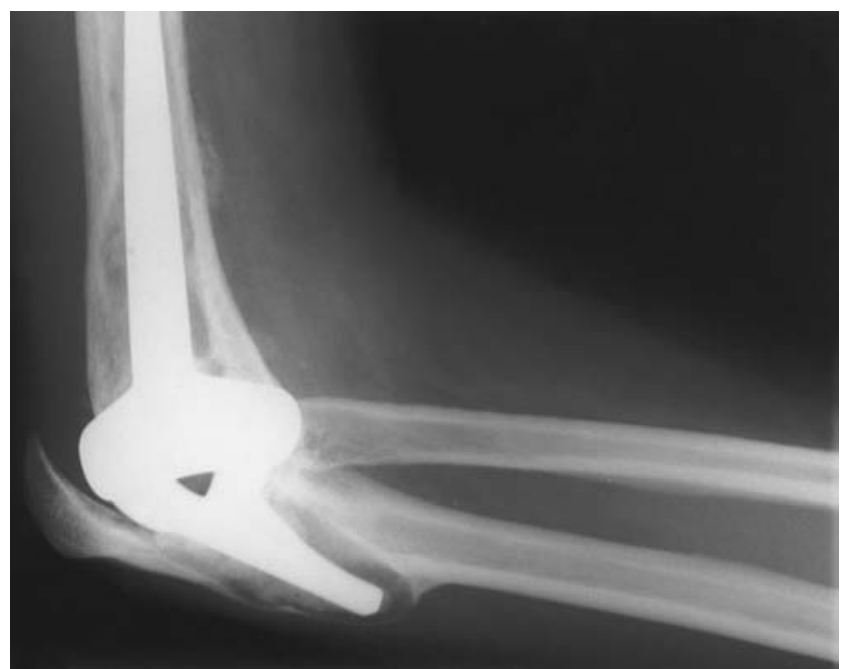

Fig. 2

Radiographs demonstrating septic loosening and migration of a Kudo prosthesis. The patient (case 1) had both HIV and Hepatitis $\mathrm{C}$ antibodies and was receiving anti-retroviral chemotherapy.

later because of progressive radiolucency and continuing pain. A one-stage revision was undertaken in order to permit a rapid return of function and to minimise the morbidity associated with a two-stage procedure. Post-operatively, the patient received intravenous vancomycin through a Hickman line for four weeks. There was no evidence of recurrent infection or failure of the revised implant 35 months later.

\section{Discussion}

Total joint arthroplasty for the hip, knee, ankle and shoulder has been commonplace in haemophilia for many years. There have been a few case reports describing replacement of the elbow joint. ${ }^{12}$

Arthroplasty of the hip or knee in the severely haemophiliac population, with native factor levels less than $1 \%$, has an increased risk of sepsis, peri-operative bleeding and loosening. Many of these patients are also infected by HIV, or Hepatitis B and C, as a direct consequence of treatment with blood products. They may be immunocompromised and require regular antibiotic and anti-retroviral medications. Such factors add to the risk of sepsis after major joint replacement. ${ }^{12}$ Surgery carries a high risk for the patients and for their attendant medical and surgical staff because of the additional risks of HIV and hepatitis infection.

Few studies have specifically attempted to address the outcome of elbow replacement in these groups. Most have described only one or two patients. ${ }^{12-16}$ Luck and Kasper ${ }^{17}$ reviewed the 20-year results of the surgical management of severely affected haemophiliacs, but only included two primary total elbow replacements. One subsequently became infected and was treated with an excision arthroplasty. The authors concluded that replacement arthroplasty should be regarded as an experimental procedure. Kasten and
Skinner ${ }^{18}$ described 34 primary and 18 revision elbow replacements but only two were in haemophiliacs. One was a primary replacement and the other a revision which was complicated by a fracture and a poor eventual outcome. Beeton et $\mathrm{al}^{4}$ in a review article on the outcome of all total joint arthroplasty procedures in haemophiliacs, mentioned these studies and two further, isolated, case reports. The recent Swedish Elbow Arthroplasty Register ${ }^{19}$ does not include data about haemophiliac patients and states that only 80 elbow arthroplasties are carried out annually in Sweden. Bajekal et $\mathrm{al}^{3}$ reported $81 \%$ of their severe haemophiliac patients suffered recurrent elbow bleeds and commented on the low incidence (23\%) of replacement arthoplasty in this group.

Our results show that certainly in the short-to-medium term, total elbow replacement may be both feasible and useful in severe haemophiliacs.

No benefits in any form have been received or will be received from a commercial party related directly or indirectly to the subject of this article.

\section{References}

1. Aronstam A, Rainsford SG, Painter MJ. Patterns of bleeding in adolescents with severe haemophilia. AA Br Med J 1979;1:469-70.

2. Atkins RM, Henderson NJ, Duthie RB. Joint contractures in the haemophilias. Clin Orthop 1987;219:97-106.

3. Bajekal R, Phillips A, Ribbans W. Elbow arthropathy in I haemophilia. Haemophilia 1996;2 (Supplement 1): 15.

4. Beeton K, Rodriguez-Merchan E, Alltree J. Total joint arthroplasty in haemophilia. Haemophilia 2000;6:474-81.

5. Butler-Manuel PA, Smith MA, Savidge GF. Silastic interposition for haemophilic arthropathy of the elbow. J Bone Joint Surg [Br] 1990; 72-B:472-4.

6. Hvid I, Rodriguez-Merchan EC. Orthopaedic surgery in haemophilic patients with inhibitors: an overview. Haemophilia 2002;8:288-91.

7. Post M, Watts G, Telfer M. Synovectomy in haemophilic arthropathy: a retrospective review of 17 cases. Clin Orthop 1986;202:139-46.

8. Rodriguez-Merchan EC, Galindo E, Magallon M, Cage J, Villar A. Resection of the radial head and partial open synovectomy of the elbow in the young adult with haemophilia. Haemophilia 1995;1:262-6.

9. Smith M, Savidge G, Fountain E. Interposition arthroplasty in the management of advanced haemophilic arthropathy of the elbow. J Bone Joint Surg [Br] 1983;65-B:436-40.

10. Street DM, Stevens PS. A humeral replacement prosthesis for the elbow: results in ten elbows. J Bone Joint Surg [Am] 1974;56-A:1147-58.

11. Le Balc'h T, Ebelin T, Laurian $\mathbf{Y}$ et al. Synovectomy of the elbow in young haemophilic patients. J Bone Joint Surg [Am] 1987;69-A:264-9.

12. Martinson A. Elbow arthroplasty in haemophilic arthritis. Thrombosis and Haemostasis 1977;38:357.

13. Merchan E, Magallon M, Manso F, Martin-Villar J. Septic arthritis in HIV positive haemophiliacs: four cases and a literature review. Int Orthop 1992;16:302-6.

14. Lofqvist T, Nilsson I, Petersson C. Orthopaedic surgery in haemophilia 20 years' experience in Sweden. Clin Orthop 1996;332:232-41.

15. Rodriguez-Merchan E. Orthopaedic surgery in haemophilia in the $21 \mathrm{st}$ century: an overview. Haemophilia 2002;8:360-8.

16. Phillips AM, Ribbans WJ, Goddard NJ. Ipsilateral total shoulder and elbow prosthetic replacement in a patient with severe haemophilia B. Haemophilia 1995;1:270-3.

17. Luck J, Kasper C. Surgical management of advanced haemophilic arthropathy: an overview of 20 years' experience. Clin Orthop 1989;242:60-82.

18. Kasten M, Skinner $\mathbf{H}$. Total elbow arthroplasty: an 18 year experience Clin Orthop 1993;290:177-88.

19. Rahme H, Jacobsen M, Salomonsson B. The Swedish elbow arthroplasty register and the Swedish shoulder arthroplasty register. Acta Orthop Scand 2001;72:107-12. 